\title{
Review of Salt Reducing and Fertility Improvement in Vegetable Facilities in Saline-alkali Land
}

\author{
Dong Xiaoxia*, Liu Shenglin and Ma Zheng \\ Institute of Agricultural Resources and Environment, Shandong Acedemy of Agricultual Sciences, China
}

*Corresponding author: Dong Xiaoxia, Ministry of Agriculture, Institute of Agricultural Resources and Environment, Shandong Academy of Agricultural Sciences, China.

Received Date: March 27, 2020

Published Date: September 30, 2020

\begin{abstract}
High salinity, low soil organic matter content and poor soil structure severely limited vegetables production in saline-alkali area. In vegetable facilities, drip irrigation could significantly induce salt content, improve water and nutrition utilization rate though forming "desalinized soil layer". Application of organic manure could alleviate salt stress by increasing soil organic matter content, promoting the formation of soil aggregate structure, decreasing $\mathrm{pH}$ and increasing nutrients in saline-alkali soil. Application of conditioner on saline-alkali soil could partly improve soil physicochemical properties with decreasing salt content.
\end{abstract}

Keyword: Desalinized soil layer; Drip irrigation; Organic manure; Soil conditioner; Saline-alkali land; Vegetable facility

\section{Introduction}

Saline-alkali area distributed in China was the 3rd largest on earth which is about 99 million hectares (ha). Most of that is distributed at arid area in northwest China (13 million ha) and sea coastal area (8 million ha) [1]. Saline-alkali soil at sea coastal area is disadvantage for the production of vegetables. Soil basic characteristics including high water soluble salt content, low soil organic matter content $(<20 \mathrm{~g} / \mathrm{kg})$, viscous structure, crusting heavy clay, poor ventilation and high soil density, which induce low soil temperature, water release speed and permeability rate, strong capillarity, inactivity soil aerobic microorganisms [2-3]. Salt tolerance of vegetables planted in facilities is weak that growth of most vegetables would be inhibited when soil salt content is more than $2 \mathrm{~g} / \mathrm{kg}$. Negative effect on germination rate, seedling time, flowering and fruiting rate, production quality were observed when soil salt content is $2-5 \mathrm{~g} / \mathrm{kg}$, and the plants were prone to premature aging, growth point atrophy, poor photosynthesis with smaller leaf area at the later stage [4]. When soil salt content is 6-10 $\mathrm{g} / \mathrm{kg}$, symptoms such as nutrient deficient, root growth inhibition appeared and in severe case, roots decay or stems and leaf wither by high salt content. Soil salinity generally results in reduction of $20 \%-30 \%$ on vegetable production, and sometimes more than $50 \%$ [5].

Otherwise, lack of freshwater resources is another major limit factor for the development of agriculture in coastal saline areas. Irrigation techniques, such as drip irrigation can effectively enhance yield while save water and fertilizer. Due to the soil types and vegetables species, micro-irrigation and fertilization techniques should be formula according to vegetables uptake water and nutrient.

\section{Discussion}

\section{Drip irrigation to leach salt}

Field experimental results showed that drip irrigation continuously drips water to form high frequency and small amount 
of water to leach soil salts, therefore the pulse gradually pushed the salts outward, resulting in the concentration of salt at the edge of the wetting edge. In case of multiple drip heads, the wetting fronts overlap each other that causing the lateral movement of salt to move downward and forming a whole plane of downward leaching salt, so $0-20 \mathrm{~cm}$ soil become "desalinized soil layer". After the formation of "desalinized soil layer", vegetables that requires high amount of fresh water was chosen to plant. The appropriate soil water content should be 20-40 Kpa (close to field water-holding capacity). Through drip irrigation to reduce salt, the salt content in the $0-20 \mathrm{~cm}$ soil layer with heavy salinity can be reduced from $7.10 \mathrm{~g} / \mathrm{kg}$ to $1.64 \mathrm{~g} / \mathrm{kg}$, forming the "desalinized soil layer" that can plant vegetable without inhibition [6]. Drip irrigation under plastic mulch in long term avoided salt accumulation caused by chemical fertilizers with flooding irrigation. $\mathrm{Na}+, \mathrm{Ca} 2+, \mathrm{Mg} 2+, \mathrm{SO} 42-$, and $\mathrm{Cl}-$ in soil decreased in negative exponential power function curve with the extension of drip irrigation years and uptake rate of water and nutrients improved significantly in saline areas [7].

\section{Organic manure application}

Application of organic manure could alleviate salt stress by increasing soil organic matter content, promoting crumb aggregate formation and decreasing soil $\mathrm{pH}$ in saline-alkali soil. Studies showed that application of organic manure was an effective method to improve saline-alkali soil fertility as it could increase soil organic matter, promote the formation of soil aggregates, improve soil structure [8], and reduce soil $\mathrm{pH}$ [9]. The result of field experiments and pot trials showed that soil pH significantly decreased and soil salt-exchangeable ion components significantly altered after application of organic manure, while soil organic matter, total nitrogen, total phosphorus and total potassium contents significantly increased on soda saline-alkali soil [10]. Long-term application of organic manure can change the composition of soil aggregate and improve the soil physicochemical properties [11].

\section{Soil conditioner supplication}

Soil conditioner could partly improve the soil physicochemical properties and decrease soil salt content on saline-alkali area. It is pivotal to choose best type and amount of soil conditioner for economical and ecological benefits [12-14]. Application of sulfurcontaining conditioner with suitable amount significantly relieved soil hardening and salinity to ameliorate the soil environment for vegetable growth and improve vegetables yield and quality in Tianjin city. Comprehensive input-output was best with applying soil conditioner of 2.25-3 t/ha [15].

It was utilized to saline-alkali soil amelioration by spraying the compound microorganism based on the coordinated degradation of organic matrix. With 5:1 ratio of organic fertilizer to soil, application with compound microorganism composed by bacillus licheniformis, pseudomonas, flavobacterium and sphingomonas with ratio of $1: 3: 3: 1$ in $0.5 \%$ concentration could enhance the utilization capacity of soil organic matter and significantly increase the number and diversity index of soil microorganisms. Vegetables biomass increased by $30.2 \%$ compared to organic fertilizer treatment after $50 \mathrm{~d}$ growth experiment [16].

\section{Conclusion}

Saline-alkali land are back-up resources for arable land to guarantee increasing food demand of increased population, therefore, it is worthy to systematic study in future. Saline-alkali soils in vegetables facilities formed "desalinized soil layer" through drip irrigation. Vegetable yield could be increased through application of organic manure, soil conditioner containing mineral or microorganism by increasing soil organic matter content, promoting soil aeration and crumb aggregate formation, and reducing soil $\mathrm{pH}$. Furthermore, studies is necessary on soil salt reducing, fertility improvement and integrating approaches on water and fertilizer in vegetable facilities at coastal saline-alkali land.

\section{Acknowledgement}

None.

\section{Conflict of Interest}

Author declare no conflict of interest.

\section{References}

1. Zhang YF, Li WY, Hu H, Chen WZ, Wang XL (2017) Research status and prospects of saline-alkali land amelioration. Jiangsu agricultural sciences 45(18): 7-10.

2. Zhang JF, Zhang DS, Chen GC, Sun H, Wang QB, et al. (2015) Investigation on distribution and biomass of halophytes at beach in Shanghai. Acta Agricultural Jiangxi 27(2): 26-29.

3. Ma LJ, Len HB, Qin J (2012) Effect of saline-alkali soil on physical and chemical properties and plant biomass of soil. Jiangsu Agricultural Sciences 40(5): 330-332.

4. Liu ZX, Dai ZY,Wang YQ, Guo FL (2014) Research progress on physiological responses of vegetables to salt stress and related mitigation measures. Journal of Changjiang Vegetables (18): 1-5.

5. Yang H, Wang CL, Gao W, Tian CY (2009) Physiological damage by salt accumulation on vegetable and preventive measures in protected area. Journal of Liaoning Agricultural College 11(2): 12-13,27.

6. Zheng DF, Gao XB, Zhang YL, Yang G, Li GS, et al. (1999) Preliminary report on the effect of drip irrigation on leaching soil salinity. Shandong Agricultural Sciences 4: 32-33,40.

7. Li WH, Wang ZH, Zheng XR, Zhang JZ (2016) Soil salinity variation characteristics of cotton field under long-term mulched drip irrigation. Transactions of the Chinese Society of Agricultural Engineering 32(10): 67-74.

8. Wang HJ (2016) Preliminary study on the development and management of saline-alkali land in Liaoning province. Agricultural Economic (12): 142-144.

9. Yang HF, Xie YL, Fan JF, Li J (2006) The research of different fertilization impact on soil fertility and yield. Chinese Agricultural Science Bulletin 22(9): 250-254. 
10. Yang M, Sun Y, Gao YS, Jiang ZD, Fan YL (2013) Effects of organic manure on improving soda saline-alkali soil. Journal of Jilin Agricultural Sciences 38(3): 43-46,62.

11. Xu YC, Shen QR (2000) Influence of long-term application of manure on the contents and distribution of organic $\mathrm{C}$, total $\mathrm{N}$ and $\mathrm{P}$ in soil particlesizes. Scientia Agricultural Sinica 33(5): 1-7.

12. Wang XJ, Dong XX, Dong L, Tian SZ, Liu SL, et al. (2016) Effects of a new soil amendment on soil physical and chemical characteristics in saline field. Shandong Agricultural Sciences 48(7): 103-105.

13. Yuan Y, Guo JB, Yin SM, Mou X (2015) Effect of soil conditioner on the growth of Lolium multiflorum. Acta Prataculturae Sineca 24(10): 206213.
14. Zhang LY, Zhao GX, Xu SY, Xu DF, Wang ZH (2005) Filtration of suitable saline-alkali soil amendments on coastal saline soil. Journal of Soil and Water Conservation 19(3): 21-23,28.

15. Cheng WJ, Wang JC, Song ZW, Zhang NM (2017) Study of effect of Peidikang soil conditioner. Journal of Tianjin Agricultural and Forest Technology 257(3): 30-32.

16. Kou YM, Dai JW, Liu SX, Wu WY, Chen J (2015) Microbial property improvement of saline-alkali soil for vegetable cultivation in Shanghai coastal area and its evaluation. Journal of Shanghai Normal University (Natural Sciences) 44(6): 599-605. 